\title{
Salivary Gland Choristoma: A Rare Finding at the Gastroesophageal Junction
}

Rachel Hanke ${ }^{1}$, Isin Comba ${ }^{1}$, Richard Henriquez ${ }^{2}$, Maria W. Crespo ${ }^{3}$, Lakhinder Bhatia ${ }^{1}$

1. Internal Medicine, University of Central Florida College of Medicine, Orlando, USA 2. Internal Medicine, University of Central Florida/HCA Healthcare GME, Orlando, USA 3. Pathology, Osceola Regional Medical Center, Kissimmee, USA

Corresponding author: Isin Comba, yagmurcomba@gmail.com

\begin{abstract}
A choristoma is a tumor-like outgrowth consisting of heterotopic, histologically mature tissue located at an anatomically unusual part of the body. Salivary gland choristoma at the gastrointestinal junction (GEJ) is an extremely rare entity with only one other case reported in the literature. In this report, we present the case of an 87-year-old female with long-standing gastroesophageal reflux disease (GERD) history who was incidentally found to have salivary gland choristoma at GEJ through an upper endoscopy-guided biopsy. We suggest that the finding of salivary gland choristoma at the GEJ could be metaplasia secondary to the patient's long-standing history of GERD with esophagitis.
\end{abstract}

Received 01/10/2020

Review began 02/04/2020 Review ended 02/18/2020 Published 02/28/2020

(c) Copyright 2020

Hanke et al. This is an open access article distributed under the terms of the Creative Commons Attribution License CC-BY 4.0., which permits unrestricted use, distribution, and reproduction in any medium, provided the original author and source are credited.
Categories: Internal Medicine, Gastroenterology

Keywords: heterotopic salivary gland, choristoma, gastroesophageal junction

\section{Introduction}

Heterotopic salivary gland tissue (HSGT) has been most commonly described in the head and neck region including the middle ear, gingiva, hard and soft palate, and external auditory canal. Malignancies arising from HSGT of the head and neck region have also been reported in the literature [1,2]. The gastrointestinal tract is an unusual site of HSGT with only a few cases reported in the literature at the following anatomic locations: lower esophagus, sigmoid colon, and rectum [3-5]. In this case report, we present a case of salivary gland choristoma at the gastrointestinal junction (GEJ), an extremely rare entity with only one other case reported in the literature [6]. Our case was diagnosed incidentally in an 87-year-old female through an upper endoscopy-guided biopsy of the nodule to exclude malignancy.

\section{Case Presentation}

An 87-year-old female presented with acute-onset left lower leg pain and swelling. The patient's past medical history was significant for gastroesophageal reflux disease GERD (she was on daily famotidine), hypertension, and chronic kidney disease. On initial evaluation, vital signs were within normal limits and stable. Her laboratory tests were remarkable for elevated serum creatinine at $1.66 \mathrm{mg} / \mathrm{dl}$, reduced estimated glomerular filtration rate at $29 \mathrm{ml} / \mathrm{min}$, and microcytic anemia with initial hemoglobin at $7.9 \mathrm{gm} / \mathrm{dL}$ and mean corpuscular volume at $75.3 \mathrm{fL}$. Further investigation revealed normal coagulation panel. The iron panel was consistent with iron deficiency anemia. Doppler ultrasound showed an acute non-occlusive deep vein thrombosis in the left common femoral and femoral and popliteal veins. She was started tentatively on a therapeutic dose of enoxaparin.

During the hospitalization, the patient underwent a gastrointestinal evaluation for acute on chronic anemia due to suspected gastrointestinal bleeding. Upper endoscopy showed a large hiatal hernia, reflux esophagitis mainly in the lower one-third of the esophagus, and a small nodularity at the GEJ (Figure 1). Biopsy of the nodule demonstrated a GEJ-type mucosa with mild-to-moderate chronic inflammation, mild acute inflammation, and focal glandular tissue consistent with heterotopic salivary gland tissue (Figure 2). No intestinal metaplasia or dysplasia was noted. 


\section{Cureus}

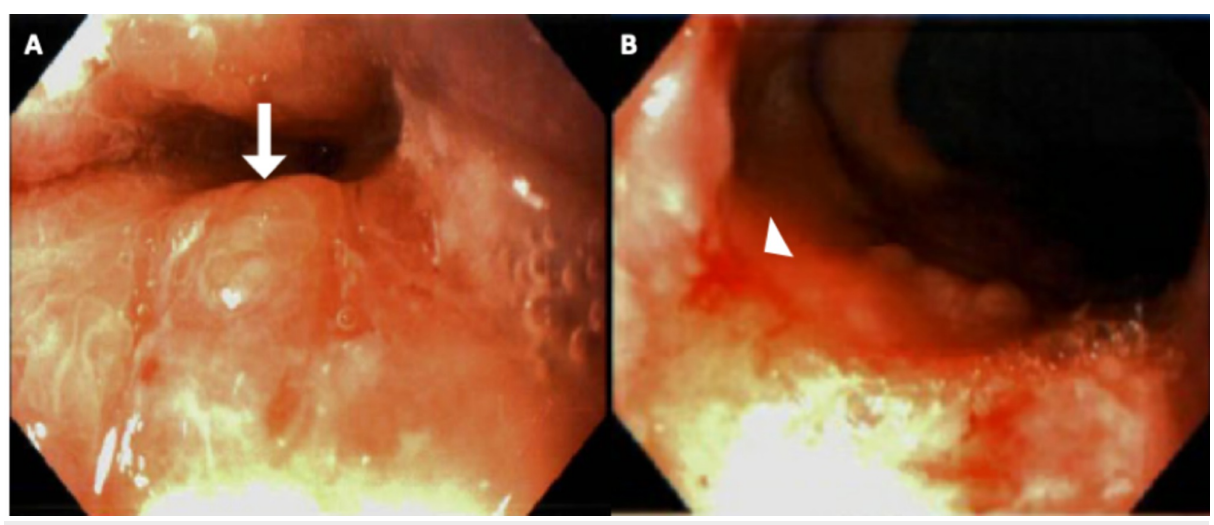

\section{FIGURE 1: EGD findings}

EGD showed a small nodule at the GEJ (A, arrow) and reflux esophagitis (B, arrowhead) in the lower one-third of the esophagus

EGD: Esophagogastroduodenoscopy; GEJ: gastrointestinal junction

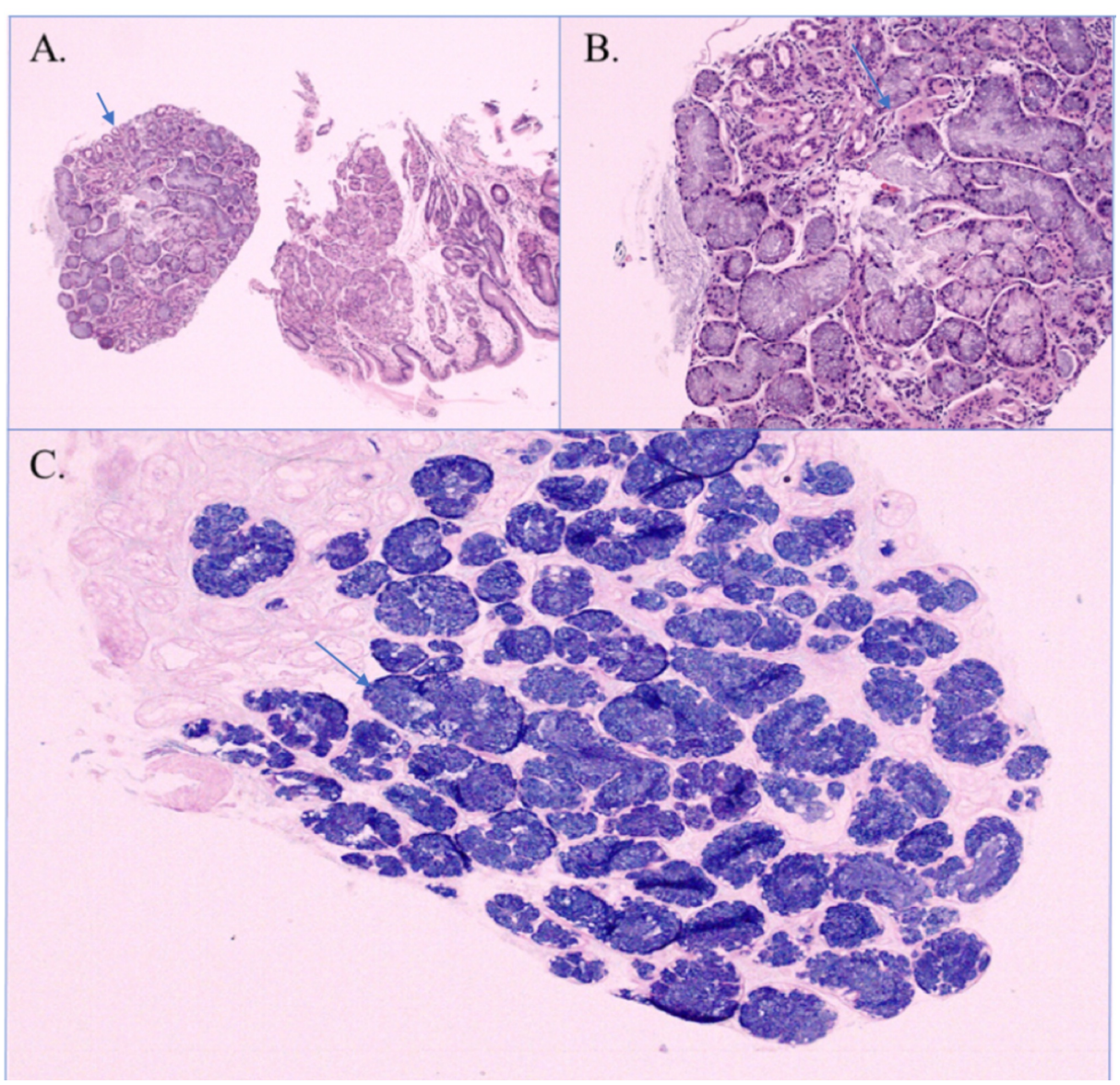

\section{FIGURE 2: Biopsy findings}

On microscopic exam of the esophageal nodule, a focal glandular tissue was noted next to the esophagogastric junction-type mucosa with mild to moderate chronic inflammation (A). The focal glandular tissue was consistent with heterotopic salivary gland tissue $(B, C)$

\section{Discussion}

The human salivary glands are composed of three major glands (the parotid, sublingual, and submandibular) and numerous minor glands that take part in food digestion, lubrication, and immune defense. It is suggested that the parotid gland originates from the oral ectoderm, while the submandibular, sublingual, 
Salivary gland choristoma at the GEJ is an extremely rare finding. Karim et al. recently reported three cases of HSGT at the GEJ, and only one of them was in the form of choristoma. All three cases presented in their report had a history of GERD, with one of the HSGT cases demonstrating grade-3 esophagitis and the other HSGT case having Barret's esophagus with high-grade dysplasia [6]. Similarly, our patient had a history of long-standing GERD with esophagitis.

Repeated exposure of the esophagus to gastric contents through reflux triggers protective mechanisms in the esophagus resembling salivary gland function. An increase in the rate of mucin release from salivary glands and esophageal mucosal and submucosal glands into the mucus-bicarbonate layer is seen with decreasing $\mathrm{pH}$ associated with GERD [7]. Exposure to gastric contents has also been found to increase the secretion of prostaglandin E2 from salivary glands [8].

It is well known in the literature that intestinal columnar metaplasia at the GEJ can occur secondary to chronic acid exposure and inflammation in the setting of GERD. The origin of these intestinal glandular cells remains unknown. The presence of multipotent stem cells or the intrinsic ability of native squamous epithelium, submucosal glands, squamocolumnar junction cells or circulating bone marrow stem cells to dedifferentiate are proposed mechanisms [9]. The latter has been supported by the fact that the embryonic esophagus is lined by columnar epithelium $[9,10]$. Furthermore, pancreatic acinar metaplasia at the GEJ is a relatively common finding, but the causative relationship between GERD and pancreatic acinar metaplasia is obscure [11]. Likewise, our patient presented with a finding of unclear origins, demonstrating the relevance of keeping salivary metaplasia in the differential and the importance of further investigations.

In this case report, we aimed to enhance the understanding of clinicians about the pathophysiology of glandular metaplasia in response to chronic inflammation at the GEJ. Development in these biological mechanisms could also contribute to studies investigating cell-based therapy for salivary gland regeneration post-radiation therapy and in patients with Sjogren's syndrome [1].

This work has been already presented as an abstract (https://insights.ovid.com/crossref?an=00000434201910001-01841).

\section{Conclusions}

We reported an extremely rare case of salivary gland choristoma at the GEJ. Based on our literature review, this finding could be a metaplastic change in the setting of chronic inflammation as a result of reflux esophagitis. However, the biological and clinical significance of the salivary gland choristoma at the GEJ is yet to be investigated. Further studies are warranted to examine the association between these two.

\section{Additional Information \\ Disclosures}

Human subjects: Consent was obtained by all participants in this study. Conflicts of interest: In compliance with the ICMJE uniform disclosure form, all authors declare the following: Payment/services info: Disclaimer: This research was supported (in whole or in part) by HCA Healthcare and/or an HCA Healthcare affiliated entity. The views expressed in this publication represent those of the author(s) and do not necessarily represent the official views of HCA Healthcare or any of its affiliated entities. Financial relationships: All authors have declared that they have no financial relationships at present or within the previous three years with any organizations that might have an interest in the submitted work. Other relationships: All authors have declared that there are no other relationships or activities that could appear to have influenced the submitted work.

\section{References}

1. Patel VN, Hoffman MP: Salivary gland development: a template for regeneration . Semin Cell Dev Biol. 2014, 25-26:52-60. 10.1016/j.semcdb.2013.12.001

2. Ferlito A, Bertino G, Rinaldo A, Mannarà GM, Devaney KO: A review of heterotopia and associated salivary gland neoplasms of the head and neck. J Laryngol Otol. 1999, 113:299-303. 10.1017/s0022215100143841

3. Wang C, Chen L, Guo W, Zhu X, Liu Z: Salivary gland choriostoma in the esophagus. Endoscopy. 2014, 46:E658-659. 10.1055/s-0034-1390842

4. Maffini F, Vingiani A, Lepanto D, Fiori G, Viale G: Salivary gland choristoma in large bowel. Endoscopy. 2012, 44:E13-14. 10.1055/s-0031-1291498

5. Downs-Kelly E, Hoschar AP, Prayson RA: Salivary gland heterotopia in the rectum. Ann Diagn Pathol. 2003, 7:124-126. 10.1053/adpa.2003.50017

6. Abdul Karim L, Kwon DH, Ozdemirli M: Salivary gland heterotopia in the gastroesophageal junction: a case series and review of the literature. Case Rep Gastrointest Med. 2018, 2018:6078581. 10.1155/2018/6078581

7. Namiot Z, Sarosiek J, Marcinkiewicz M, Edmunds MC, McCallum RW: Declined human esophageal mucin secretion in patients with severe reflux esophagitis. Dig Dis Sci. 1994, 39:2523-2529. 10.1007/bf02087685

8. Namiot Z, Yu ZJ, Piascik R, Hetzel DP, McCallum RW, Sarosiek J: Modulatory effect of esophageal 


\section{Cureus}

intraluminal mechanical and chemical stressors on salivary prostaglandin E2 in humans. Am J Med Sci.

1997, 313:90-98. 10.1097/00000441-199702000-00004

9. Rhee H, Wang DH: Cellular origins of Barrett's esophagus: the search continues . Curr Gastroenterol Rep. 2018, 20:51. 10.1007/s11894-018-0657-2

10. Guillem PG: How to make a Barrett esophagus: pathophysiology of columnar metaplasia of the esophagus . Dig Dis Sci. 2005, 50:415-424. 10.1007/s10620-005-2451-x

11. Johansson J, Håkansson HO, Mellblom L, et al.: Pancreatic acinar metaplasia in the distal oesophagus and the gastric cardia: prevalence, predictors and relation to GORD. J Gastroenterol. 2010, 45:291-299.

10.1007/s00535-009-0161-4 